\title{
Are Attractive People Rewarding? Sex Differences in the Neural Substrates of Facial Attractiveness
}

\author{
J. Cloutier, T. F. Heatherton, P. J. Whalen, and W. M. Kelley \\ Department of Psychological and Brain Sciences, Center for Cognitive Neuroscience, Dartmouth \\ College
}

\begin{abstract}
The current study examined the neural substrates of facial attractiveness judgments. Based on the extant behavioral literature, it was hypothesized that brain regions involved in identifying the potential reward value of a stimulus would be more active when males viewed attractive females than when females viewed attractive males. To test this hypothesis, we conducted an event-related functional magnetic resonance imaging (fMRI) experiment during which participants provided explicit attractiveness judgments for faces of the opposite sex. These individual ratings were subsequently used to perform analyses aimed at identifying the brain regions preferentially responsive to attractive faces for both sex groups. The results revealed that brain regions comprising the putative reward circuitry (e.g., Nucleus Accumbens [NAcc], Orbitofrontal Cortex $[\mathrm{OFC}])$ showed a linear increase in activation with increased judgments of attractiveness. However, further analysis also revealed sex differences in the recruitment of OFC which distinguished attractive and unattractive faces only for male participants.
\end{abstract}

Among the numerous socially relevant dimensions extracted from faces, facial attractiveness has a profound influence on how we construe newly encountered individuals (Dion et al., 1972; Feingold, 1992; Jackson et al., 1995). Facial attractiveness and the positively-valenced stereotypical information with which it is typically associated is believed to come to mind spontaneously upon encountering attractive individuals (van Leeuwen and Macrae, 2004; Olson and Marshuetz, 2005).

The importance of attractiveness in social interactions is well documented. Indeed, as perceivers we tend to be positively biased towards attractive individuals (Langlois et al., 2000). Notably, even infants seem to favor attractive faces. When presented with a pair of stimuli composed of an attractive and an unattractive face, infants will spend more time looking at the most attractive of the two (Langlois et al., 1987; Langlois et al., 1991). This preference for attractive faces in infants suggests that the perceptual processes used to identify facial attractiveness are, at least partly, acquired early in life. In adulthood, the positive biases towards attractive individuals manifest themselves in multiple areas of social life (Langlois et al., 2000). For example, attractive people are perceived as being more competent, as possessing better social skills, and as such, they tend to receive better salaries and have more mating success (Dion et al., 1972; Landy and Sigall, 1974; Eagly et al., 1991; Hamermesh and Biddle, 1994; Rhodes et al., 2005). Accordingly, the important societal implications of attractiveness has motivated multiple investigations aimed at uncovering exactly what makes faces attractive and identifying the mechanisms allowing attractiveness to exert such an influence on social interactions (Rhodes and Zebrowitz, 2002). 
From the standpoint of evolutionary social psychology, facial attractiveness is generally believed to indicate the genetic fitness and reproductive capacities of encountered individuals (Fink and Penton-Voak, 2002; Rhodes, 2006). However, when selecting mates, men place greater importance on attractiveness than do women, whereas women favor status and resources more so than men (Buss, 1989; Buss and Schmitt, 1993; Sprecher et al., 1994; $\mathrm{Li}$ et al., 2002). Although the reasons behind these differences can be explained from both evolutionary and socio-cultural perspectives (Howard et al., 1987), the mechanisms underlying these sex differences are still not fully understood (Buss, 1989). One possibility is that attractive faces of the opposite sex simply have different reward value for males and females. This notion is supported by a recent study showing that males are willing to wait longer, will exchange more money, and will expend more effort than females for the opportunity to look at attractive opposite-sex faces (Hayden et al., 2007). Furthermore, it has been shown that males, but not females, are motivated by the presence of an attractive face of the opposite sex to discount higher future monetary rewards in favor of smaller immediate monetary rewards (Wilson and Daly, 2004).

An extensive body of research with non-human primates has demonstrated the involvement of specific brain areas in various phases of reward-related perception and action (Rolls, 2000; Schultz, 2000; Schultz et al., 2000). Specifically, the nucleus accumbens (NAcc) and the orbitofrontal cortex (OFC) are believed to play an important role in the processing and evaluation of reward signals. In humans, activity in the NAcc and the OFC has been associated with the maintenance of drug addictions (Breiter et al., 1997; London et al., 2000; Volkow and Fowler, 2000; Wise, 2002), suggesting that these brain areas also play an important role in a putative human reward circuitry. A number of fMRI studies have also demonstrated the involvement of the NAcc and the OFC when participants anticipate and/or receive secondary rewards such as money (Knutson et al., 2001; O’Doherty et al., 2001; Elliott et al., 2004).

Interestingly, facial attractiveness has also been linked to brain areas involved in reward processing (Aharon et al., 2001; Kampe et al., 2001; O’Doherty et al., 2003b; Kranz and Ishai, 2006; Winston et al., 2007). Aharon and colleagues (2001) conducted a blockeddesign fMRI experiment during which male participants alternated between passively viewing epochs of average and attractive female and male faces. Results revealed that male participants preferentially activate the NAcc and the OFC when perceiving attractive female faces and support the claim that attractive faces are processed by some of the same brain areas as other rewarding stimuli. Although other fMRI studies investigating the perception of facial attractiveness have consistently reported the involvement of the OFC (Kampe et al., 2001; O'Doherty et al., 2003; Winston et al., 2007), involvement of the NAcc during the perception of attractiveness has not yet been replicated.

If the proposed hypothesis that males find opposite-sex faces more rewarding than females is correct (Wilson and Daly, 2004), there should be sex differences in the extent that components of the putative reward circuitry are recruited when processing attractive faces. Thus far, however, few studies have identified sex differences in the recruitment of reward related brain areas for the processing of opposite-sex facial attractiveness. Kranz and Ishai (2006) investigated potential sex and sexual orientation differences in the neural substrate underlying the perception of opposite-sex faces. Although they found that faces of the sexually preferred gender preferentially activated the OFC, they did not find sex differences in the activation of this region. Subsequent analysis of this data (Ishai, 2007) revealed that perceivers preferentially recruit the OFC when presented with attractive faces of the sexually preferred gender compared to attractive faces of the non-preferred gender. Interestingly, Winston and colleagues (2007) recently demonstrated that males perceiving attractive faces of both sexes recruit an area of the anterior cingulate cortex more than 
females perceiving the same faces. Nevertheless, in light of studies of mate preferences demonstrating that males value attractiveness more than females (Buss, 1989; Sprecher et al., 1994; Li et al., 2002), it is surprising that no sex differences in the activation of either the NAcc or the OFC was uncovered by studies examining the perception of facial attractiveness (Ishai, 2007).

The current study used an event-related fMRI design to identify sex differences in the neural substrate underlying the processing of facial attractiveness. To do so, female and male participants were presented with faces of the opposite sex varying on attractiveness. By presenting only opposite-sex faces to a relatively large number of participants, we attempted to maximize the ability to identify the various components of the putative reward circuitry recruited during the perception of facial attractiveness.

\section{METHODS}

\section{Subjects}

Fifty-two subjects between the ages of 19 and 27 were recruited from the local Dartmouth community. Four were excluded from analyses, one due to excessive movement $(>1 \mathrm{~mm}$ between successive scans) and three for not complying with the behavioral task instructions. Of the remaining 48 subjects, 24 were female (mean age $=20.7$ years) and 24 were male (mean age $=22.7$ years). Subjects reported no abnormal neurological history, had normal or corrected-to-normal visual acuity, and subjects were strongly right-handed as measured by the Edinburgh Handedness Inventory (Oldfield, 1971; Raczkowski et al., 1974). Subjects received course credit or were paid for their participation and gave informed consent in accordance with the guidelines set by the Committee for the Protection of Human Subjects at Dartmouth College.

\section{Functional Imaging}

Anatomical and functional whole-brain imaging was performed on a 3-T Philips Intera Achieva Scanner (Phillips Medical Systems, Bothell, WA) equipped with a SENSE (SENSEitivity Encoding) head coil. An Apple Powerbook computer running PSYSCOPE V. 1.2.5 (Cohen et al., 1993) was used for stimulus display. Stimuli were projected to subjects with an Epson (model ELP-7000) LCD projector onto a screen positioned at the head end of the bore. Subjects viewed the screen through a mirror mounted on the head coil. Cushions were used to minimize head movement.

Anatomical images were acquired using a high-resolution 3-D magnetization-prepared rapid gradient echo sequence (MPRAGE; 160 sagittal slices, TE $=4.6 \mathrm{msec}$, TR $=9.9 \mathrm{msec}$, flip angle $=8^{\circ}$, voxel size $=1 \times 1 \times 1 \mathrm{~mm}$ ). Functional images were collected in two runs using T2* fast field echo, echo planar functional images (EPIs) sensitive to BOLD contrast (TR = $2500 \mathrm{msec}, \mathrm{TE}=35 \mathrm{msec}$, flip angle $=90^{\circ}, 3 \times 3 \mathrm{~mm}$ in-plane resolution, sense factor of 2; 96 sets of images). Slices were acquired axially allowing whole brain coverage (45 slices; 3.5-mm slice thickness, $0.5 \mathrm{~mm}$ skip between slices).

\section{Behavioral Task}

During scanning, subjects judged the attractiveness of 90 faces of the opposite sex. Face stimuli consisted of a set of unfamiliar non-namable faces used in previous neuroimaging studies (Kelley et al., 1998; Wig et al., 2004) that was complemented with other unfamiliar faces compiled from the media. The faces were cropped below the chin line and around the outer hairline and were scaled to center a $1333 \times 1333 \mathrm{~mm}$ black canvas. All faces displayed direct eye gaze, were equated on familiarity, nameability and emotional expressions (depicting either a neutral expression or a slight smile), and were selected to represent a 
range of attractiveness based on a norming study in 62 participants $(19$ males, mean age $=$ 19.2 years old; 43 females, mean age $=18.8$ years old). During the experiment, faces were presented for $2000 \mathrm{msec}$ and were followed by a centrally presented fixation crosshair for $500 \mathrm{msec}$. Face trials were pseudorandomly interspersed with fixation trials consisting of a fixation crosshair presented for $2500 \mathrm{msec}$ to introduce jitter into the fMRI time series (Ollinger et al., 2001). This resulted in a mean ITI of $3000 \mathrm{msec}$ (range $=500 \mathrm{msec}$ to 5500 msec) Subjects responded to each face presentation via a four-button fiber optic key press, using the scale $1=$ very attractive through $4=$ not attractive at all. For purposes of our analysis of variance (ANOVA), items evoking a response of 1 or 2 were collapsed and considered attractive, whereas items evoking a response of 3 or 4 were considered unattractive.

\section{Data Analysis}

fMRI data were analyzed using the general linear model for event-related designs in SPM2 (Wellcome Department of Cognitive Neurology, London, UK) (Friston et al., 1995). For each functional run, data were preprocessed to remove sources of noise and artifact. Functional data were corrected for differences in acquisition time between slices for each whole-brain volume, realigned within and across runs to correct for head movement, and coregistered with each participant's anatomical data. Functional data were then transformed into a standard anatomical space (3-mm isotropic voxels) based on the ICBM 152 brain template (Montreal Neurological Institute) that approximates Talairach and Tournoux's atlas space (Talairach and Tournoux, 1988). Normalized data were then spatially smoothed (6$\mathrm{mm}$ full width at half maximum) using a Gaussian kernel. Analyses took place at two levels: formation of statistical images and regional analysis of hemodynamic responses.

The purpose of the first analysis was to identify brain regions whose activity tracked linearly with increasing and decreasing attractiveness. In this first analysis, a general linear model incorporating a single task effect (face presentation), a parametric regressor (indicating subjects' response to each face) and covariates of no interest (a session mean, a linear trend, and six movement parameters derived from realignment corrections), was used to compute parameter estimates $(\beta)$ and t-contrast images (containing weighted parameter estimates) for each comparison at each voxel for every subject. In this way, the height of the expected hemodynamic response function was parametrically adjusted for all face events as a function of each subject's attractiveness ratings for each face. To identify additional brain regions that responded to facial attractiveness in a non-linear fashion (e.g., amygdala, Winston et al., 2007), parametric modulations using a series of polynomial expansions of the subjectspecific attractiveness face ratings (Buchel et al., 1998) were examined.

A second analysis was performed to identify brain regions sensitive to facial attractiveness as a function of participants' gender. In this second analysis, face trials were collapsed into attractive (faces that received a 1 or 2 response from the subject) and unattractive (faces that received a 3 or 4 response) categories. For each participant, a general linear model, incorporating these two task effects (modeled with a canonical hemodynamic response function; Friston, Fletcher, et al., 1998) and covariates of no interest (a session mean, a linear trend, and six movement parameters derived from realignment corrections) were used to compute parameter estimates $(\beta)$ and t-contrast images (containing weighted parameter estimates) for each comparison at each voxel. These individual contrast images were then submitted to a second-level random-effects analysis to create mean $t$ images (thresholded at $\mathrm{P}<0.005$, minimum cluster size $=5$ voxels). To obtain signal change values for the attractive and unattractive face trials, spherical regions of interest (ROIs) (4mm for NAcc and the amygdala, $8 \mathrm{~mm}$ for other regions) were defined based on peaks identified in the parametric analysis. In this way, each gender group contributed equally to the generation of ROIs. Mean signal intensity values for each trial type of interest were then extracted from 
each ROI and were submitted to a 2 (sex: female, male) x 2 (face category: attractive, unattractive) ANOVA with repeated measures on the second factor.

\section{RESULTS}

\section{Behavioral Results}

Comparisons between the percentage of responses made by female and male participants at each attractiveness level $(1=$ very attractive; through $4=$ not attractive at all $)$ were performed. Results revealed a significant group difference only for the fourth judgment level $(1: \mathrm{t}[46]=.60, \mathrm{p}=.55 ; 2: \mathrm{t}[46]=1.64, \mathrm{p}=.11 ; 3: \mathrm{t}[46]=.94, \mathrm{p}=.35 ; 4: \mathrm{t}[46]=3.60,=$. 001) such that female participants made more 4 (not attractive at all) judgments than male participants (Figure 1, top graph). Additionally, a 2 (gender: female, male) x 4 (judgment levels: 1: very attractive; through 4: not attractive at all) ANOVA with repeated measures on the second factor was performed on the speed of subjects' responses. Results revealed, a main effect of judgment levels $(F[3,138] 19.58, \mathrm{p}=0.001)$. There was no main effect of gender $(F[1,46] 2.21, p=0.143)$ and no gender $x$ judgment level interaction $(F<1)$ (Figure 1 , bottom graph). Pair-wise comparisons performed on the main effect of judgment levels revealed significant differences between levels, such that participants were slower when endorsing intermediate levels (i.e., 2 and 3 judgments) than extreme levels (i.e., 1 and 4 judgments $)(2>1, \mathrm{t}[47]=7.20, \mathrm{p}<0.001 ; 2>4, \mathrm{t}[47]=6.20, \mathrm{p}<0.001 ; 3>1, \mathrm{t}[47]=$ $3.82, \mathrm{p}<0.001 ; 3>4, \mathrm{t}[47]=5.36, \mathrm{p}<0.001)$. There were no significant differences between the two intermediate judgments ( 2 versus $3, \mathrm{t}[47]=1.06, \mathrm{p}=.29)$ and between the two extreme judgments ( 1 versus $4, \mathrm{t}[47]=.63, \mathrm{p}=.53)$.

\section{fMRI Results}

Two fMRI analyses were performed. To identify brain regions that showed a linear change in activity with increasing or decreasing judgments of attractiveness, attractiveness ratings for each face (1-4) were considered as a parametric regressor. Results revealed that activity in brain regions previously found to be associated with the processing of facial attractiveness increased in a linear fashion with increasing attractiveness judgments (Figure 2, Table 1). Specifically, activations were observed in the NAcc bilaterally (left NAcc: $-9,8,-8$; right NAcc: 9, 14, -6,), the dorsal ACC (Brodmann's Area [BA] 24: 3, 33, 9), a region the medial prefrontal cortex (MPFC, BA 32: 9, 46, -12), and the OFC (BA 11: $-9,40,-15)^{1}$. These regions can be distinguished from the lateralized activations observed in the primary motor cortex, thalamus, and cerebellum that were consistent with the left- and right-handed button presses (Table 1).

To determine whether brain regions that were preferentially responsive to facial attractiveness differed as a function of subjects' gender, a ROI analysis was conducted. Specifically, ROIs were defined based on peak activations in the parametric analysis. Signal intensities for each ROI were calculated separately for the presentation of attractive (judgments 1 and 2) and unattractive (judgments 3 and 4) faces and examined statistically using a 2 (subject gender: female, male) x 2 (face category: attractive, unattractive) ANOVA with repeated measures on the second factor.

Results revealed that the OFC preferentially responded to attractive faces, but only for male subjects (Figure 3). This region showed a main effect of attractiveness, $(F[1,46]=12.11, P<$

\footnotetext{
${ }^{1}$ Consistent with prior work by Winston and colleagues (2007), bilateral regions of the amygdala (x y z coordinates, left: $-24,-4$, -15 ; right: $27,-1,-13)$ demonstrated a significant $(\mathrm{P}<0.001)$ nonlinear relationship with attractiveness such that activity was greater for the most and least attractive faces than for faces of average attractiveness.
} 
$0.01)$, no main effect of subject gender, $(\mathrm{F}[1,46]=1.89, \mathrm{P}=0.18)$ and an interaction between attractiveness and gender $(\mathrm{F}[1,46]=4.54, \mathrm{P}<0.05)$.

By contrast, the left and right NAcc responded preferentially to attractive faces regardless of the subjects' gender (Figure 3). Both NAcc regions revealed a main effect of attractiveness, (left NAcc: $\mathrm{F}[1,46]=11.73$, P < 0.001); right NAcc: $\mathrm{F}[1,46]=11.35$, $\mathrm{P}<0.005$ ), no main effect of subject gender (left NAcc: $F[1,46]=3.69, \mathrm{P}=0.06$ ); right NAcc: $\mathrm{F}[1,46]=1.09, \mathrm{P}$ $=0.30$ ), and no interaction (left and right NAcc: Both F's < 1).

Similar activation patterns were observed in the MPFC and ACC. Both region revealed a main effect of attractiveness (MPFC: F[1,46] = 5.21, P < 0.05; ACC: $F[1,46]=29.15$, P < 0.001), no main effect of subject gender and no interaction (All F's $<1$ ).

Finally, the reverse pattern (greater activity to unattractive than attractive faces, regardless of gender) was observed in a separate region of the right lateral OFC (BA 47; 45, 26, -14). This region showed a main effect of attractiveness $(F[1,46]=3.95, P=0.05)$, no main effect of subject gender, and no interaction (both F's $<1$ ).

\section{DISCUSSION}

These findings demonstrate that multiple components of the putative human reward circuitry are involved in the processing of facial attractiveness. Whereas activity in the majority of these regions discriminates between attractive and unattractive faces of the opposite gender in both male and female participants, activity in the OFC did so only in male participants. We consider each region separately.

\section{Nucleus Accumbens (NAcc)}

The current study provides evidence that NAcc activity indexes facial attractiveness and appears to do so in a parametric fashion. This finding may help reconcile what has been a mixed pattern of results in neuroimaging studies of facial attractiveness. Whereas one study (Aharon et al., 2001) has reported NAcc activity when individuals viewed opposite-sex faces, other studies have not.

One possible explanation for the disparate findings in previous work is differences in experimental paradigms across studies. Whereas Aharon and colleagues (2001) employed a blocked design, other studies adopted event-related paradigms. On the surface, such differences might seem trivial, however, differences in NAcc activity across paradigms would be expected if the NAcc is preferentially sensitive to the expectation of reward, a process that would operate between events and would be less sensitive to the detection or representation of reward values (O'Doherty et al., 2003). Given that the present study employed an event-related paradigm and observed NAcc activity that was time-locked to individual presentations of faces, such an account seems unlikely.

An alternative account is that intermixing male and female faces impacts NAcc responsivity. Previous studies of facial attractiveness in which faces of both sex were intermixed failed to observe NAcc activity (Kampe et al., 2001; O’Doherty et al., 2003; Kranz \& Ishai, 2006). Because the reward value of attractive faces may serve a functional role in mate selection, it is possible that exclusively viewing faces of the opposite sex (e.g., (Aharon et al., 2001) encourages individuals to consider their potential mate value. Put simply, the putative reward value of opposite-sex faces may differ depending on the context in which the faces are experienced. Face presentations in the present study were purposefully restricted to opposite-sex faces to minimize such potential context differences. 
Although there was some evidence to suggest that NAcc would index facial attractiveness in the present study (at least in response to opposite-sex faces), it was somewhat surprising that NAcc activity in response to attractive faces did not differ as a function of subjects' gender. Much of the behavioral work investigating gender differences in response to attractiveness highlights strategy differences when considering the suitability of potential mates. Whereas males emphasize attractiveness more than females when considering potential mates, females emphasize status, resources, and social dominance more than males (Buss and Schmitt, 1993; Mazur et al., 1994; Sprecher et al., 1994; Li et al., 2002). NAcc activity appears to be insensitive to such differences. One possibility is that NAcc activity may provide a more fundamental (i.e., bottom-up) representation of reward signal that is subsequently evaluated to varying degrees in other cortical regions (e.g., OFC) depending on the importance of the appraisal to the evaluator. Such an account affords the flexibility needed to detect or represent the wide range of rewarding stimuli to which the NAcc responds. For example, in non-human primates, cells in the striatum respond to both the expectation and the presentation of a variety of rewards, including liquid or food (Schultz et al., 2000). Furthermore, in humans, the presentation of rewarding stimuli such as money activates the NAcc (Delgado et al., 2000; Knutson et al., 2001; Galvan et al., 2005).

\section{Medial Prefrontal Cortex (MPFC)}

Activity in a region of the MPFC increased with increasing levels of facial attractiveness. Regions of the MPFC have previously been involved in decision-making tasks involving monetary reward (Rogers et al., 2004), have been shown to support self-reflection (Gusnard et al., 2001; Johnson et al., 2002; Kelley et al., 2002; Macrae et al., 2004; Heatherton et al., 2006; Moran et al., 2006) and daydreaming (McGuire et al., 1996; Mason et al., 2007), and are believed to be recruited when mentalizing about similar others (Mitchell et al., 2006). To the extent that participants prefer to mentalize about attractive faces more than unattractive faces, MPFC activity may be sensitive to this process.

\section{Anterior Cingulate Cortex (ACC)}

The current study also found that the ACC preferentially responds to attractive faces irrespective of the participant's sex. The genual and subgenual ACC have been shown to play a role in affective processing (Whalen et al., 1998; Bush, 2000) that might entail the monitoring of internal autonomic states (Critchley, 2004). In the present study, ACC activity may reflect an increase in internal monitoring of autonomic states, a notion that is consistent with the observed increase in MPFC activity to attractive faces. Human neuroimaging work has suggested that the dACC is tonically active during task performance (Dosenbach et al., 2006) and sensitive to processing outcomes, particularly the commission of errors (Carter et al., 1998; Botvinick et al., 2001; Bush et al., 2002; Gehring and Willoughby, 2002; Badre and Wagner, 2004; Botvinick et al., 2004; Holroyd et al., 2004; Kerns et al., 2004; van Schie et al., 2004; Williams et al., 2004; Brown and Braver, 2005; Dosenbach et al., 2006; Somerville et al., 2006). More recently, work in non-human primates has demonstrated a putative roll for the ACC in learning and integrating reward outcomes to shape future behavior (Kennerley et al., 2006). When considered in the context of these findings, ACC activity observed in the present study may reflect trial-to-trial learning in service of defining levels of attractiveness (i.e., what constitutes attractive for this particular cohort of faces).

\section{Orbital Frontal Cortex (OFC)}

Whereas activity in the NAcc, ACC, and MPFC indexed facial attractiveness independent of subjects' gender, activity in OFC did so only for males. The OFC is believed to play a central role in "evaluating the reward-value of ongoing behavior," (Dolan, 1999), and has been implicated in reward-based, motivated social behavior (Arana et al., 2003; Kringelbach and Rolls, 2004) and emotion-based decision making (Bechara et al., 1997). In both non- 
human primates and humans, the OFC has been shown to increase its activity with the increasing reward value of juice (Roesch and Olson, 2004) and money (O’Doherty et al., 2001) respectively.

One speculation is that differences in the pattern of OFC activity across subject gender reflect underlying behavioral differences in the extent to which males and females consider attractiveness to be rewarding. Although, on the surface, both gender groups ostensibly performed the same judgment task, the criteria by which attractiveness judgments were made likely differed across the two groups. Whereas males may have emphasized sexual appeal in their judgments of opposite-sex faces, females may have adhered to a more straightforward, aesthetic assessment of facial attractiveness. For example, facial dominance appears to influence the perception of opposite-sex individuals in female perceivers (Reis and et al., 1982; Keating, 1985; Mazur et al., 1994; Perrett et al., 1998; Senior et al., 1999; Johnston et al., 2001; Swaddle and Reierson, 2002). Although we did not collect dominance ratings for the face stimuli used here, such differences, whether intentional or implicit, would be expected to manifest as functional anatomic differences in brain regions sensitive to reward evaluation.

Interestingly, behavioral studies have demonstrated that females can and do change their priorities, attributing more importance to attractiveness when asked to judge its importance in selecting short-term instead of long-term partners. In so doing, sex differences between males and females are eliminated ( $\mathrm{Li}$ and Kenrick, 2006). Similarly, the different stages of the female menstrual cycle impact judgments of person perception (Macrae et al., 2002; Senior et al., 2007), including face and potential mate preferences (Penton-Voak et al., 1999; Gangestad et al., 2007). An open question for future neuroimaging investigations of facial attractiveness is whether the gender difference observed in OFC can be eliminated by equating the underlying criteria used by each gender to make attractiveness judgments. It is also worth noting that the gender differences in OFC activity were observed without regard to the sexual orientation of the perceiver. Although we attempted to recruit only heterosexual participants by explicitly recruiting individuals to participate in a study investigating opposite-sex facial attractiveness, a detailed assessment of sexual preference (Sell et al., 1995), was not conducted due to participant confidentiality concerns raised by the Committee for the Protection of Human Subjects at Dartmouth College. Thus, future work is needed to determine whether the effects reported here truly reflect sex differences between females and males or whether the effects index differences in sexual preference for female and male faces (Kranz and Ishai, 2006).

\section{Lateral OFC}

Consistent with the results obtained by O'Doherty and colleagues (2003), a lateral region of the OFC was shown to increase in activity with decreasing attractiveness judgments. Collectively, these findings support the proposed dissociation between the involvement of medial OFC in reward and lateral OFC in punishment (O'Doherty et al., 2001; Kim et al., 2004; Kringelbach and Rolls, 2004). Furthermore, the lateral OFC is also believed to play an important role in inhibiting or reversing the effects of unwanted or unexpected information (Cools et al., 2002; Kringelbach and Rolls, 2003; O’Doherty et al., 2003a; Ochsner and Gross, 2005). In the context of the present study, activity in the lateral OFC may reflect attempts by the participants to inhibit ensuing negative affect following the presentation of unattractive faces.

\section{Conclusions}

The current investigation provides supporting evidence that brain regions sensitive to reward are recruited during the perception of attractive faces (Senior, 2003). Indeed, in conjunction 
with the results obtained in previous studies of facial attractiveness (Aharon et al., 2001; Kampe et al., 2001; O'Doherty et al., 2003; Kranz \& Ishai, 2006; Winston et al., 2007), the current findings suggest that a network of brain areas including the NAcc, the ACC, the MPFC, and the OFC, are involved in processing the attractiveness of faces. The present findings extend prior work in this domain by demonstrating that increases in OFC activity for attractive faces are restricted to male participants. This sex difference in mOFC activity may provide a potential mechanism underlying the reason why males identify attractiveness as a stronger motivation in mate selection (Buss, 1989; Li et al., 2002).

\section{References}

Aharon I, Etcoff N, Ariely D, Chabris CF, O'Connor E, Breiter HC. Beautiful faces have variable reward value: fMRI and behavioral evidence. Neuron. 2001; 32:537-551. [PubMed: 11709163]

Arana FS, Parkinson JA, Hinton E, Holland AJ, Owen AM, Roberts AC. Dissociable contributions of the human amygdala and orbitofrontal cortex to incentive motivation and goal selection. J Neurosci. 2003; 23:9632-9638. [PubMed: 14573543]

Badre D, Wagner AD. Selection, integration, and conflict monitoring; assessing the nature and generality of prefrontal cognitive control mechanisms. Neuron. 2004; 41:473-487. [PubMed: 14766185]

Bechara A, Damasio H, Tranel D, Damasio AR. Deciding advantageously before knowing the advantageous strategy. Science. 1997; 275:1293-1295. [PubMed: 9036851]

Botvinick MM, Cohen JD, Carter CS. Conflict monitoring and anterior cingulate cortex: an update. Trends in Cognitive Science. 2004; 8:539-546.

Botvinick MM, Braver TS, Barch DM, Carter CS, Cohen JD. Conflict monitoring and cognitive control. Psychological Review. 2001; 108:624-652. [PubMed: 11488380]

Breiter HC, Gollub RL, Weisskoff RM, Kennedy DN, Makris N, Berke JD, Goodman JM, Kantor HL, Gastfriend DR, Riorden JP, Mathew RT, Rosen BR, Hyman SE. Acute effects of cocaine on human brain activity and emotion. Neuron. 1997; 19:591-611. [PubMed: 9331351]

Brown JW, Braver TS. Learned predictions of error likelihood in the anterior cingulate cortex. Science. 2005; 307:1118-1121. [PubMed: 15718473]

Buchel C, Holmes AP, Rees G, Friston KJ. Characterizing stimulus-response functions using nonlinear regressors in parametric fMRI experiments. Neuroimage. 1998; 8:140-148. [PubMed: 9740757]

Bush G, Vogt BA, Holmes J, Dale AM, Greve D, Jenike MA, Rosen BR. Dorsal anterior cingulate cortex: a role in reward-based decision making. Proc Natl Acad Sci U S A. 2002; 99:523-528. [PubMed: 11756669]

Bush G, Luu P, Posner MI. Cognitive and emotional influences in the anterior cingulate cortex. Trends in Cognitive Sciences. 2000; 4:215-222. [PubMed: 10827444]

Buss DM. Sex differences in human mate preferences: Evolutionary hypotheses tested in 37 cultures. Behavioral and Brain Sciences. 1989; 12:1-49.

Buss DM, Schmitt DP. Sexual strategies theory: an evolutionary perspective on human mating. Psychol Rev. 1993; 100:204-232. [PubMed: 8483982]

Carter CS, Braver TS, Barch DM, Botvinick MM, Noll D, Cohen JD. Anterior cingulate cortex, error detection, and the online monitoring of performance. Science. 1998; 280:747-749. [PubMed: 9563953]

Cohen JD, MacWhinney B, Flatt M, Provost J. Psyscope: A new graphic interactive environment for designing psychology experiments. Behavioral Research Methods, Instruments, and Computers. 1993; 25:257-271.

Cools R, Clark L, Owen AM, Robbins TW. Defining the neural mechanisms of probabilistic reversal learning using event-related functional magnetic resonance imaging. J Neurosci. 2002; 22:45634567. [PubMed: 12040063]

Critchley HD. The human cortex responds to an interoceptive challenge. Proc Natl Acad Sci U S A. 2004; 101:6333-6334. [PubMed: 15096592] 
Delgado MR, Nystrom LE, Fissell C, Noll DC, Fiez JA. Tracking the hemodynamic responses to reward and punishment in the striatum. J Neurophysiol. 2000; 84:3072-3077. [PubMed: 11110834]

Dion K, Berscheid E, Walster E. What is beautiful is good. Journal of Personality and Social Psychology. 1972; 24:285-290. [PubMed: 4655540]

Dolan RJ. On the neurology of morals. Nat Neurosci. 1999; 2:927-929. [PubMed: 10526323]

Dosenbach NU, Visscher KM, Palmer ED, Miezin FM, Wenger KK, Kang HC, Burgund ED, Grimes AL, Schlaggar BL, Petersen SE. A core system for the implementation of task sets. Neuron. 2006; 50:799-812. [PubMed: 16731517]

Eagly AH, Ashmore RD, Makhijani MG, Longo LC. What is beautiful is good, but....: A metaanalytic review of research on the physical attractiveness stereotype. Psychological Bulletin. 1991; 110:109-128.

Elliott R, Newman JL, Longe OA, William Deakin JF. Instrumental responding for rewards is associated with enhanced neuronal response in subcortical reward systems. Neuroimage. 2004; 21:984-990. [PubMed: 15006665]

Feingold A. Good-looking people are not what we think. Psychological Bulletin. 1992; 111:304-341.

Fink B, Penton-Voak I. Evolutionary psychology of facial attractiveness. Current Directions in Psychological Science. 2002; 11:154-158.

Friston KJ, Holmes AP, Poline JB, Grasby PJ, Williams SC, Frackowiak RS, Turner R. Analysis of fMRI time-series revisited. Neuroimage. 1995; 2:45-53. [PubMed: 9343589]

Galvan A, Hare TA, Davidson M, Spicer J, Glover G, Casey BJ. The role of ventral frontostriatal circuitry in reward-based learning in humans. J Neurosci. 2005; 25:8650-8656. [PubMed: 16177032]

Gangestad SW, Garver-Apgar CE, Simpson JA, Cousins AJ. Changes in Women's Mate Preferences Across the Ovulatory Cycle. Journal of Personality and Social Psychology. 2007; 92:151-163. [PubMed: 17201549]

Gehring WJ, Willoughby AR. The medial frontal cortex and the rapid processing of monetary gains and losses. Science. 2002; 295:2279-2282. [PubMed: 11910116]

Gusnard DA, Akbudak E, Shulman GL, Raichle ME. Medial prefrontal cortex and self-referential mental activity: relation to a default mode of brain function. Proc Natl Acad Sci U S A. 2001; 98:4259-4264. [PubMed: 11259662]

Hamermesh DS, Biddle JE. Beauty and the Labor Market. American Economic Review. 1994; 84:1174-1194.

Hayden BY, Parikh PC, Deaner RO, Platt ML. Economic principles motivating social attention in humans. Proc Biol Sci. 2007; 274:1751-1756. [PubMed: 17490943]

Heatherton TF, Wyland CL, Macrae CN, Demos KE, Denny BT, Kelley WM. Medial prefrontal activity differentiates self from close others. Social Cognitive and Affective Neuroscience. 2006; 1:18-25. [PubMed: 18985097]

Holroyd CB, Nieuwenhuis S, Yeung N, Nystrom L, Mars RB, Coles MG, Cohen JD. Dorsal anterior cingulate cortex shows fMRI response to internal and external error signals. Nat Neurosci. 2004; 7:497-498. [PubMed: 15097995]

Howard JA, Blumstein P, Schwartz P. Social or evolutionary theories? Some observations on preferences in human mate selection. Journal of Personality and Social Psychology. 1987; 53:194200.

Ishai A. Sex, beauty and the orbitofrontal cortex. Int J Psychophysiol. 2007; 63:181-185. [PubMed: 16759727]

Jackson LA, Hunter JE, Hodge CN. Physical attractiveness and intellectual competence: A metaanalytic review. Social Psychology Quarterly. 1995; 58:108-122.

Johnson SC, Baxter LC, Wilder LS, Pipe JG, Heiserman JE, Prigatano GP. Neural correlates of selfreflection. Brain. 2002; 125:1808-1814. [PubMed: 12135971]

Johnston VS, Hagel R, Franklin M, Fink B, Grammer K. Male facial attractiveness: Evidence for hormone-mediated adaptive design. Evolution and Human Behavior. 2001; 22:251-267. 
Kampe KK, Frith CD, Dolan RJ, Frith U. Reward value of attractiveness and gaze. Nature. 2001; 413:589. [PubMed: 11595937]

Keating CF. Gender and the physiognomy of dominance and attractiveness. Social Psychology Quarterly. 1985; 48:61-70.

Kelley WM, Macrae CN, Wyland CL, Caglar S, Inati S, Heatherton TF. Finding the self? An eventrelated fMRI study. J Cogn Neurosci. 2002; 14:785-794. [PubMed: 12167262]

Kelley WM, Miezin FM, McDermott KB, Buckner RL, Raichle ME, Cohen NJ, Ollinger JM, Akbudak E, Conturo TE, Snyder AZ, Petersen SE. Hemispheric specialization in human dorsal frontal cortex and medial temporal lobe for verbal and nonverbal memory encoding. Neuron. 1998; 20:927-936. [PubMed: 9620697]

Kerns JG, Cohen JD, MacDonald AW 3rd, Cho RY, Stenger VA, Carter CS. Anterior cingulate conflict monitoring and adjustments in control. Science. 2004; 303:1023-1026. [PubMed: 14963333]

Kim H, Somerville LH, Johnstone T, Polis S, Alexander AL, Shin LM, Whalen PJ. Contextual modulation of amygdala responsivity to surprised faces. J Cogn Neurosci. 2004; 16:1730-1745. [PubMed: 15701225]

Knutson B, Adams CM, Fong GW, Hommer D. Anticipation of increasing monetary reward selectively recruits nucleus accumbens. J Neurosci. 2001; 21:RC159. [PubMed: 11459880]

Kranz F, Ishai A. Face perception is modulated by sexual preference. Curr Biol. 2006; 16:63-68. [PubMed: 16401423]

Kringelbach ML, Rolls ET. Neural correlates of rapid reversal learning in a simple model of human social interaction. Neuroimage. 2003; 20:1371-1383. [PubMed: 14568506]

Kringelbach ML, Rolls ET. The functional neuroanatomy of the human orbitofrontal cortex: evidence from neuroimaging and neuropsychology. Prog Neurobiol. 2004; 72:341-372. [PubMed: 15157726]

Landy D, Sigall H. Beauty is talent: Task evaluation as a function of the performer's physical attractiveness. Journal of Personality and Social Psychology. 1974; 29:299-304.

Langlois JH, Ritter JM, Roggman LA, Vaughn LS. Facial diversity and infant preferences for attractive faces. Developmental Psychology. 1991; 27:79-84.

Langlois JH, Roggman LA, Casey RJ, Ritter JM, et al. Infant preferences for attractive faces: Rudiments of a stereotype? Developmental Psychology. 1987; 23:363-369.

Langlois JH, Kalakanis L, Rubenstein AJ, Larson A, Hallam M, Smoot M. Maxims or myths of beauty? A meta-analytic and theoretical review. Psychological Bulletin. 2000; 126:390-423. [PubMed: 10825783]

Li NP, Kenrick DT. Sex similarities and differences in preferences for short-term mates: what, whether, and why. J Pers Soc Psychol. 2006; 90:468-489. [PubMed: 16594832]

Li NP, Bailey JM, Kenrick DT, Linsenmeier JA. The necessities and luxuries of mate preferences: testing the tradeoffs. J Pers Soc Psychol. 2002; 82:947-955. [PubMed: 12051582]

London ED, Ernst M, Grant S, Bonson K, Weinstein A. Orbitofrontal cortex and human drug abuse: functional imaging. Cereb Cortex. 2000; 10:334-342. [PubMed: 10731228]

Macrae CN, Alnwick KA, Milne AB, Schloerscheidt AM. Person perception across the menstrual cycle: Hormonal influences on social-cognitive functioning. Psychological Science. 2002; 13:532536. [PubMed: 12430837]

Macrae CN, Moran JM, Heatherton TF, Banfield JF, Kelley WM. Medial prefrontal activity predicts memory for self. Cereb Cortex. 2004; 14:647-654. [PubMed: 15084488]

Mason MF, Norton MI, Van Horn JD, Wegner DM, Grafton ST, Macrae CN. Wandering minds: the default network and stimulus-independent thought. Science. 2007; 315:393-395. [PubMed: 17234951]

Mazur A, Halpern C, Udry JR. Dominant looking male teenagers copulate earlier. Ethology \& Sociobiology. 1994; 15:87-94.

McGuire PK, Paulesu E, Frackowiak RS, Frith CD. Brain activity during stimulus independent thought. Neuroreport. 1996; 7:2095-2099. [PubMed: 8930966] 
Mitchell JP, Macrae CN, Banaji MR. Dissociable medial prefrontal contributions to judgments of similar and dissimilar others. Neuron. 2006; 50:655-663. [PubMed: 16701214]

Moran JM, Macrae CN, Heatherton TF, Wyland CL, Kelley WM. Neuroanatomical evidence for distinct cognitive and affective components of self. J Cogn Neurosci. 2006; 18:1586-1594. [PubMed: 16989558]

O'Doherty J, Critchley H, Deichmann R, Dolan RJ. Dissociating valence of outcome from behavioral control in human orbital and ventral prefrontal cortices. J Neurosci. 2003a; 23:7931-7939. [PubMed: 12944524]

O’Doherty J, Kringelbach ML, Rolls ET, Hornak J, Andrews C. Abstract reward and punishment representations in the human orbitofrontal cortex. Nat Neurosci. 2001; 4:95-102. [PubMed: $11135651]$

O'Doherty J, Winston J, Critchley H, Perrett D, Burt DM, Dolan RJ. Beauty in a smile: the role of medial orbitofrontal cortex in facial attractiveness. Neuropsychologia. 2003b; 41:147-155. [PubMed: 12459213]

Ochsner KN, Gross JJ. The cognitive control of emotion. Trends Cogn Sci. 2005; 9:242-249. [PubMed: 15866151]

Oldfield RC. The assessment and analysis of handedness: the Edinburgh inventory. Neuropsychologia. 1971; 9:97-113. [PubMed: 5146491]

Ollinger JM, Shulman GL, Corbetta M. Separating processes within a trial in event-related functional MRI. Neuroimage. 2001; 13:210-217. [PubMed: 11133323]

Olson IR, Marshuetz C. Facial Attractiveness Is Appraised in a Glance. Emotion. 2005; 5:498-502. [PubMed: 16366753]

Penton-Voak IS, Perrett DI, Castles DL, Kobayashi T, Burt DM, Murray LK, Minamisawa R. Menstrual cycle alters face preference. Nature. 1999; 399:741-742. [PubMed: 10391238]

Perrett DI, Lee KJ, Penton-Voak I, Rowland D, Yoshikawa S, Burt DM, Henzi SP, Castles DL, Akamatsu S. Effects of sexual dimorphism on facial attractiveness. Nature. 1998; 394:884-887. [PubMed: 9732869]

Raczkowski D, Kalat JW, Nebes R. Reliability and validity of some handedness questionnaire items. Neuropsychologia. 1974; 12:43-47. [PubMed: 4821188]

Reis HT, et al. Physical attractiveness in social interaction: II. Why does appearance affect social experience? Journal of Personality and Social Psychology. 1982; 43:979-996.

Rhodes G. The evolutionary psychology of facial beauty. Annual Review of Psychology. 2006; 57:199-226.

Rhodes, G.; Zebrowitz, LA., editors. Facial attrativeness: Evolutionary, cognitive, and social perspectives. Westport, CT: Ablex Publishing; 2002.

Rhodes G, Simmons LW, Peters M. Attractiveness and sexual behavior: Does attractiveness enhance mating success? Evolution and Human Behavior. 2005; 26:186-201.

Roesch MR, Olson CR. Neuronal activity related to reward value and motivation in primate frontal cortex. Science. 2004; 304:307-310. [PubMed: 15073380]

Rogers RD, Ramnani N, Mackay C, Wilson JL, Jezzard P, Carter CS, Smith SM. Distinct portions of anterior cingulate cortex and medial prefrontal cortex are activated by reward processing in separable phases of decision-making cognition. Biol Psychiatry. 2004; 55:594-602. [PubMed: 15013828]

Rolls ET. The orbitofrontal cortex and reward. Cereb Cortex. 2000; 10:284-294. [PubMed: 10731223]

Schultz W. Multiple reward signals in the brain. Nat Rev Neurosci. 2000; 1:199-207. [PubMed: 11257908]

Schultz W, Tremblay L, Hollerman JR. Reward processing in primate orbitofrontal cortex and basal ganglia. Cereb Cortex. 2000; 10:272-284. [PubMed: 10731222]

Sell RL, Wells JA, Wypij D. The prevalence of homosexual behavior and attraction in the United States, the United Kingdom and France: Results of national population-based samples. Archives of Sexual Behavior. 1995; 24:235-248. [PubMed: 7611844]

Senior C. Beauty in the brain of the beholder. Neuron. 2003; 38:525-528. [PubMed: 12765605] 
Senior C, Lau A, Butler MJR. The effects of the menstrual cycle on social decision making. International Journal of Psychophysiology. 2007; 63:186-191. [PubMed: 16815580]

Senior C, Barnes J, Jenkins R, Landau S, Phillips ML, David AS. Attribution of social dominance and maleness to schematic faces. Social Behavior and Personality. 1999; 27:331-338.

Somerville LH, Heatherton TF, Kelley WM. Anterior cingulate cortex responds differentially to expectancy violation and social rejection. Nat Neurosci. 200610.1038/nn1728

Sprecher S, Sullivan Q, Hatfield E. Mate selection preferences: gender differences examined in a national sample. J Pers Soc Psychol. 1994; 66:1074-1080. [PubMed: 8046577]

Swaddle JP, Reierson GW. Testosterone increases perceived dominance but not attractiveness in human males. Proc Biol Sci. 2002; 269:2285-2289. [PubMed: 12495494]

Talairach, J.; Tournoux, P. Co-planar stereotaxic atlas of the human brain. New York, NY: Thieme Medical Publishers; 1988.

van Leeuwen ML, Macrae CN. Is Beautiful Always Good? Implicit Benefits of Facial Attractiveness. Social Cognition. 2004; 22:637-649.

van Schie HT, Mars RB, Coles MG, Bekkering H. Modulation of activity in medial frontal and motor cortices during error observation. Nat Neurosci. 2004; 7:549-554. [PubMed: 15107858]

Volkow ND, Fowler JS. Addiction, a disease of compulsion and drive: involvement of the orbitofrontal cortex. Cereb Cortex. 2000; 10:318-325. [PubMed: 10731226]

Whalen PJ, Bush G, McNally RJ, Wilhelm S, McInerney SC, Jenike MA, Rauch SL. The emotional counting Stroop paradigm: a functional magnetic resonance imaging probe of the anterior cingulate affective division. Biol Psychiatry. 1998; 44:1219-1228. [PubMed: 9861465]

Wig GS, Miller MB, Kingstone A, Kelley WM. Separable routes to human memory formation: dissociating task and material contributions in the prefrontal cortex. J Cogn Neurosci. 2004; 16:139-148. [PubMed: 15006043]

Williams ZM, Bush G, Rauch SL, Cosgrove GR, Eskandar EN. Human anterior cingulate neurons and the integration of monetary reward with motor responses. Nat Neurosci. 2004; 7:1370-1375. [PubMed: 15558064]

Wilson M, Daly M. Do pretty women inspire men to discount the future? Proc Biol Sci. 2004; 271(Suppl 4):S177-179. [PubMed: 15252976]

Winston JS, O’Doherty J, Kilner JM, Perrett DI, Dolan RJ. Brain systems for assessing facial attractiveness. Neuropsychologia. 2007; 45:195-206. [PubMed: 16828125]

Wise RA. Brain reward circuitry: insights from unsensed incentives. Neuron. 2002; 36:229-240.

[PubMed: 12383779] 


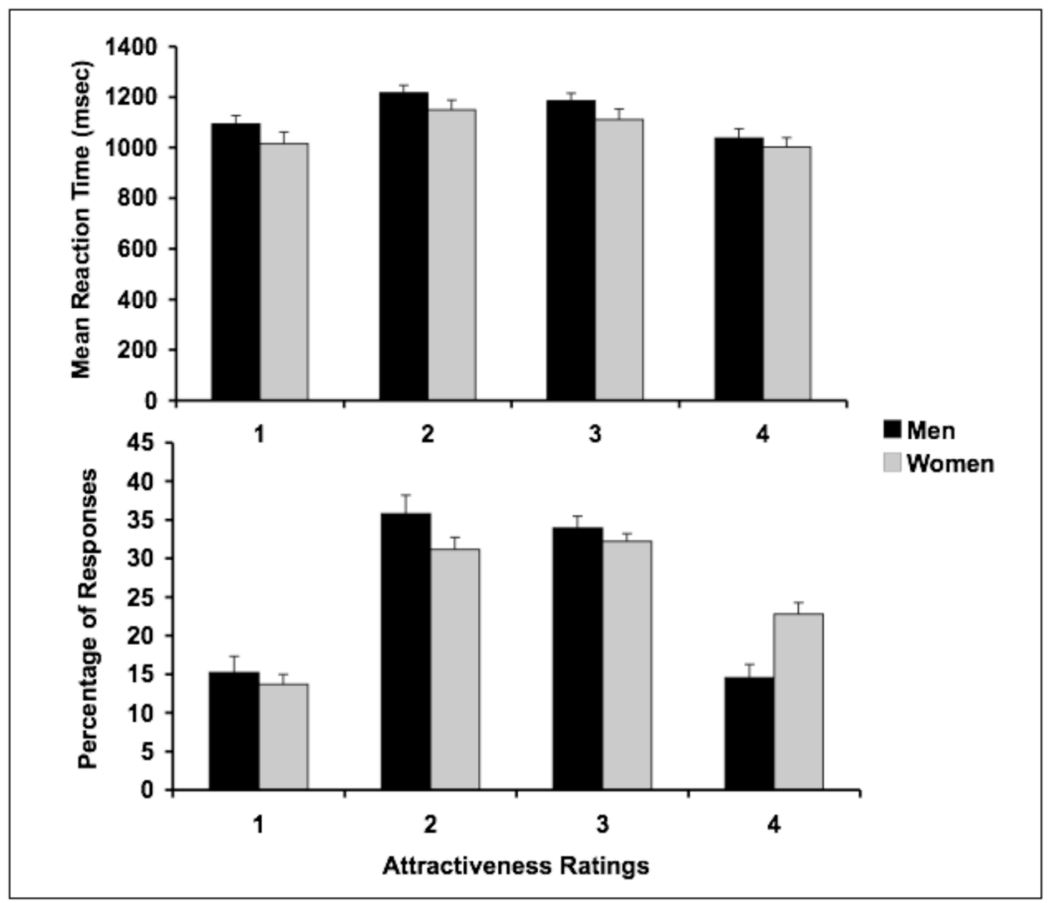

Figure 1.

Top: Response latencies for attractiveness ratings $(1=$ Very attractive; $4=$ Not attractive at all) were not significantly different between male and female participants. Bottom: Percentage of responses attributed to each attractiveness rating level was only significantly different between male and female participants for response 4 (Not attractive at all), with females making more of these responses than males. 


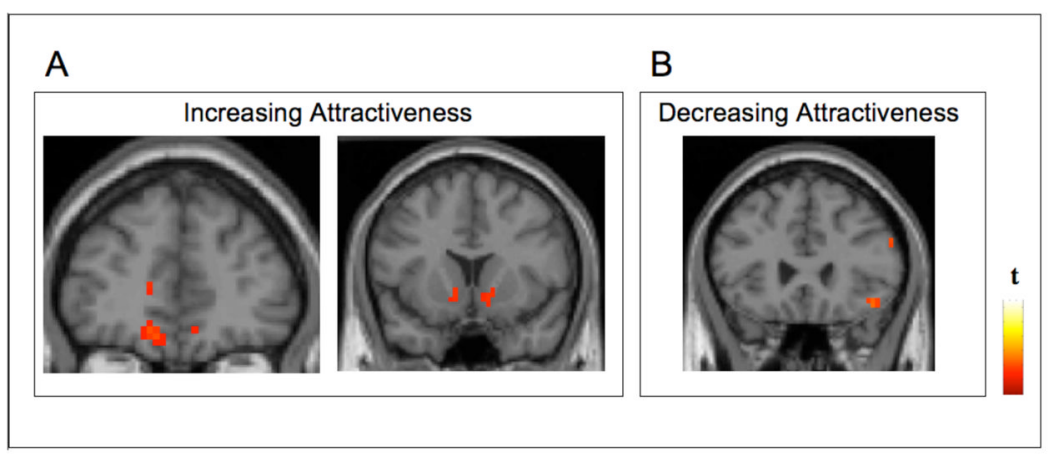

Figure 2.

(A) Coronal sections illustrating regions that increased their activity as a function of increasing judgments of attractiveness. The left OFC (BA11: -9 $40-15$ ) and bilateral NAcc (left: $-98-5$; right: $914-3$ ) showed this pattern of activity. (B) Coronal sections illustrating regions that increased their activity as a function of decreasing judgments of attractiveness. The right lateral OFC (BA47: 45 26 -11) and right middle frontal gyrus (BA32: 5042 17), showed this pattern of activity. 


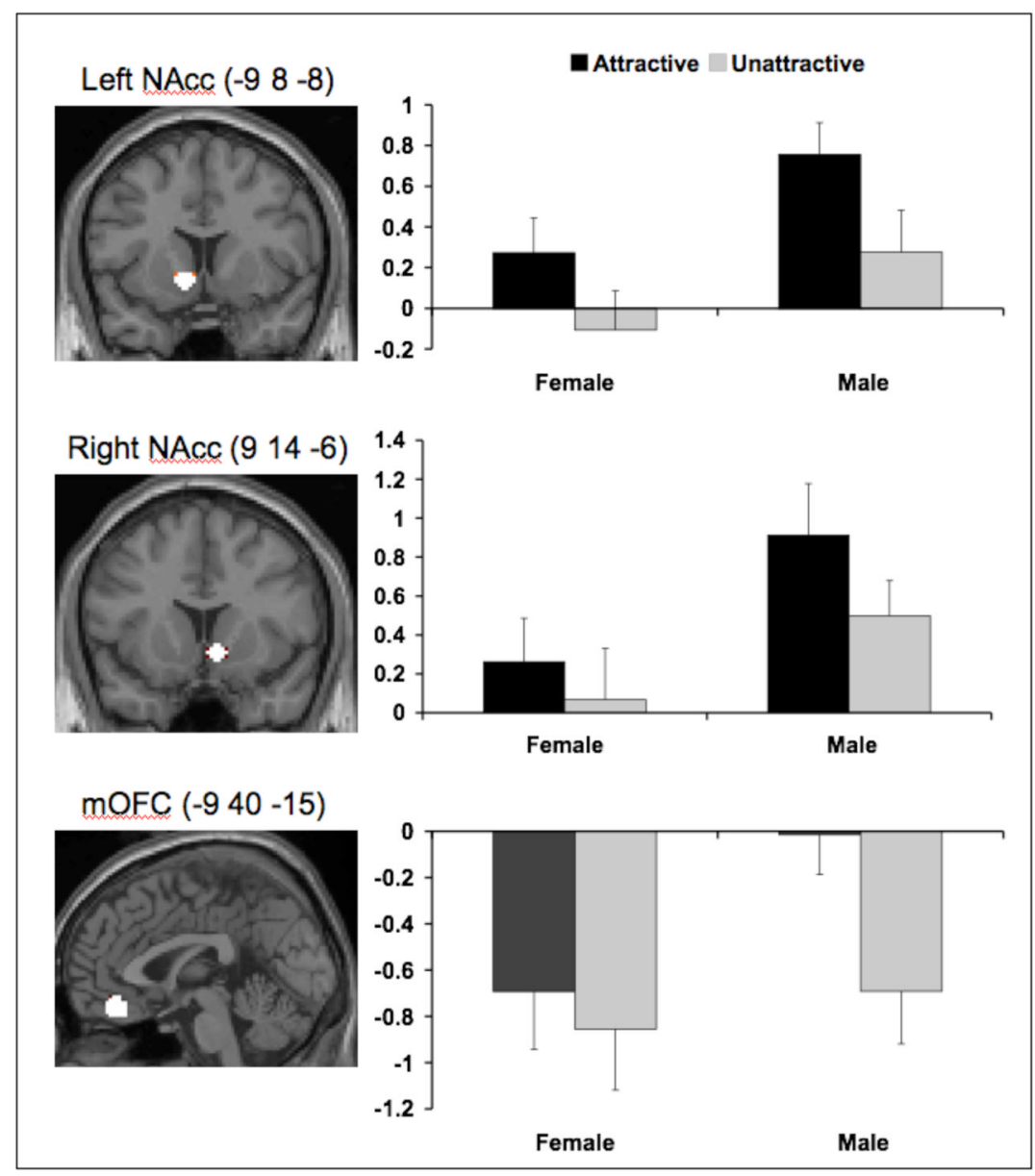

Figure 3.

Axial sections display left NAcc (top) and right NAcc (middle) and a sagittal section displays mOFC (bottom) spherical regions of interest superimposed on normalized anatomic images. Graphs to the right of each image display signal change (parameter estimates) for attractive and unattractive faces across female and male participants relative to the baseline fixation. Error bars indicate standard error of the mean. Activity in the left and right NAcc was greater for attractive than unattractive faces irrespective or the participants' gender. Activity in the mOFC exhibited an interaction between facial attractiveness and participant gender displaying greater activity for attractive than unattractive faces only for male participants. 


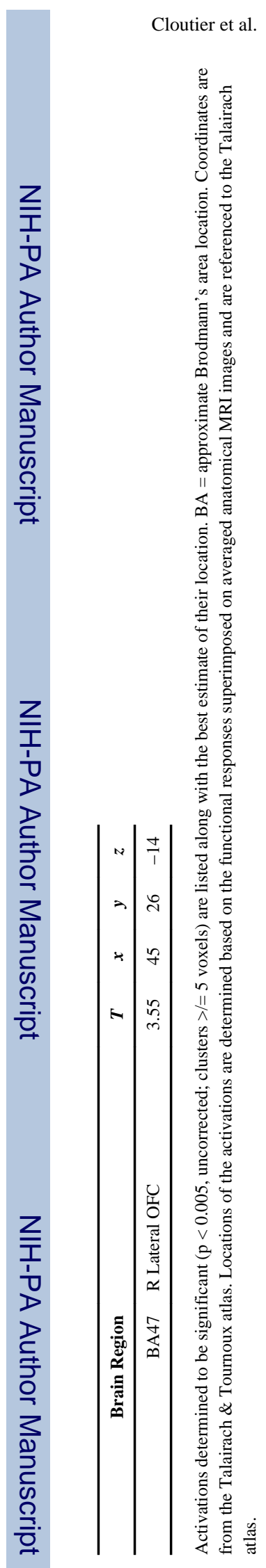

Page 18 